\title{
COMPARATIVE EVALUATION OF TRANSCUTANEOUS ELECTRICAL NERVE STIMULATION (TENS) V/S NON-STEROIDAL ANTI-INFLAMMATORY DRUGS (NSAIDS) FOR POSTOPERATIVE PAIN MANAGEMENT IN OPEN CHOLECYSTECTOMY
}

\author{
Hans Raj Ranga ${ }^{1}$, Sunil Yadav², Deepak Kumar Garg 3 , Pradeep Garg 4
}

${ }^{1}$ Associate Professor, Department of General Surgery, Pt. B. D. Sharma PGIMS, Rohtak, Haryana.

${ }^{2}$ Senior Resident, Department of General Surgery, Pt. B. D. Sharma PGIMS, Rohtak, Haryana.

$3 J u n i o r$ Resident, Department of General Surgery, Pt. B. D. Sharma PGIMS, Rohtak, Haryana.

${ }^{4}$ Senior Professor, Department of General Surgery, Pt. B. D. Sharma PGIMS, Rohtak, Haryana.

\section{ABSTRACT}

\section{BACKGROUND}

Pain is not only an unpleasant sensation but also increases morbidity of any operation like atelectasis, ileus, requirement of intensive care and increase in hospital stay. By neuro-modulation based on the gate control theory, we can achieve the similar results as with pharmaceutics without their side effects. Aim of this study was to compare the Non-Steroidal Anti-Inflammatory Drug (NSAID) with Transcutaneous Nerve Stimulation (TENS) in terms of postoperative pain and duration of pain relief by using a visual analogue scale.

\section{MATERIAL AND METHODS}

Our study included open cholecystectomy patients, 25 patients in each group (Groups I with NSAID, group II with TENS use). The lower limit of age was 20 years. All patients who underwent open cholecystectomy and above 20 years of age without any comorbidities were included in the study. Data was analysed by using SPSS software version 16.

\section{RESULTS}

In TENS therapy group, patient's acceptance was $84 \%$. Patients in group I had a higher VAS score and less duration of pain relief than group II at 24 and 48 hours (VAS $=4 \mathrm{v} / \mathrm{s} 2$, duration of pain relief $=8.0$ and 8.8 hours v/s 10.8 and 11.2 hours). Average numbers of application for the group I was higher than group II (3 v/s 2.1). Both showed no complications of pain equal physiologic parameters like pulse and blood pressure, so both modalities were effective in controlling pain.

\section{CONCLUSION}

TENS can be used without analgesic for the postoperative pain of cholecystectomy with good patient acceptance and effectiveness.

\section{KEYWORDS}

Tens, NSAID’S, Open Cholecystectomy, Postoperative Pain.

HOW TO CITE THIS ARTICLE: Ranga HR, Yadav S, Garg DK, et al. Comparative evaluation of transcutaneous electrical nerve stimulation (TENS) v/s non-steroidal anti-inflammatory drugs (NSAIDS) for postoperative pain management in open cholecystectomy. J. Evolution Med. Dent. Sci. 2016;5(47):2972-2975, DOI: 10.14260/jemds/2016/693

\section{INTRODUCTION}

Pain is a major symptom in several medical conditions and can significantly interfere with quality of life, general functioning and outcomes of medical or surgical illness. Nowadays, so many options are available for management of opioids, non-steroidal anti-inflammatory drug (NSAID), regional and local analgesics, but all of them are either associated with significant side effects or require the services of the skilled anaesthesiologist.

Electrical stimulation for pain control was first described in ancient Greece in 63 A.D. It was reported by Scribonius Largus, that pain was relieved by standing on the seashore near an electrical fish.[1]

Financial or Other, Competing Interest: None.

Submission 20-04-2016, Peer Review 19-05-2016,

Acceptance 26-05-2016, Published 11-06-2016.

Corresponding Author:

Dr. Deepak Kumar Garg,

Junior Resident

Department of General Surgery,

Room No. 155, Doctor's Hostel, PGIMS, Rohtak,

Haryana-124001.

E-mail: deep21dude@yahoo.co.in

DOI: $10.14260 /$ jemds/2016/693
Transcutaneous Electrical Nerve Stimulation (TENS) stimulates nerve endings by electrical stimulation and works on gate theory of pain relief.[2] The analgesic effect of TENS has been found to be dependent on duration, intensity, frequency of stimulation and location of electrodes.[3] While previous systemic review, Reeve et al concluded that there is little if any evidence in favour of TENS for postoperative analgesia.[4], but Bjordal et al found that these reviews were based on evaluation model that included trials with possible ineffective treatment dose and they recommended that TENS administered with a strong subnoxious intensity at an adequate frequency in the wound area can significantly reduce analgesic consumption for postoperative pain. [5] Prior reports show that TENS reduce pain through both peripheral and central mechanisms. Centrally, sites in the spinal cord and brainstem that utilize opioid, serotonin and muscarinic receptors are activated by TENS peripherally, whereas at the site of TENS application, opioid and $\alpha-2$ noradrenergic receptors are involved in TENS-induced analgesia..6] TENS therapy stimulates large, fast, myelinated, non-nociceptive neurons in the painful area, thus "Closing the central gate" for those stimuli generated by pain specific fibers. 
This system associated with the activation of an endogenous opioid system is supposed to be responsible for the analgesic effect of the TENS.[7]

TENS use electric current produced by a device to stimulate the nerves for therapeutic purposes. TENS by definition covers the complete range of transcutaneously applied currents used for nerve excitation, although the term is often used with a more restrictive intent, namely to describe the kind of pulses produced by portable stimulators used to treat pain and the unit is usually connected to the skin using two or more electrodes. A typical battery-operated TENS unit is able to modulate pulse width, frequency and intensity. Generally, TENS are applied at high frequency ( $>50$ HZ) with an intensity below motor contraction (Sensory intensity) or low frequency $(<10 \mathrm{~Hz})$ with an intensity that produces motor contraction. ${ }^{[8]}$

\section{MATERIAL AND METHODS}

The aim of our study was to compare the effectiveness of TENS in postoperative pain management for open cholecystectomy in comparison to NSAIDS in terms of duration and severity of pain on a visual analogue scale. Sample size estimation was based on the assumption that a 2.5-point difference between treatment groups on the visual analogue scale would be clinically significant. Assuming a standard deviation of 2.25 points, an alpha of 0.05 and a beta of 0.20 (Power of 0.80 ), sample size was estimated at 21 patients per group. [9] To account for losses, 25 patients were entered into each group. All patients included in this study after their approval and signing a written consent form. Our study included 50 patients of open cholecystectomy during the August 2012 to December 2014 from a tertiary care center, which was approved by the Ethics Committe of our university (Pt. B. D. Sharma PGIMS Rohtak Haryana, India). Data processed by using SPSS software version 16 and using student's T test and ANOVA.

Our study included the patients in group I $(n=25)$ received NSAIDS, i.e. in diclofenac $75 \mathrm{mg}$ IM thrice a day for 2 days. The patients in group II $(n=25)$ treated with TENS twice daily or whenever required for 2 days.

\section{Inclusion Criteria}

1. All patients with cholelithiasis planned for open cholecystectomy.

\section{Exclusion Criteria}

1. Patients under 20 years.

2. The comorbidities like a subhepatic drain, choledocholithiasis, cardiac and psychiatric illness.

3. Not willing to give consent.

The first phase of TENS was performed in group II patients, first at 2 hours postoperatively and then subsequently twice daily or whenever required and those patients who did not get relief were given analgesics and counted as non-responsive. All applications of TENS were noted. The stimulators (dual channel TENS Bioten Inc. Istanbul, Turkey) were used. The electrodes of TENS were placed with an adhesive gel on either side of the incision site. The treatment was conventional TENS therapy and each cycle lasted for 30 minutes. The day-to-day assessment was performed and pulse rate and blood pressure, systolic as well as diastolic were recorded preoperatively, immediate postoperative period and on a postoperative day 1 and day 2 . An assessment was done on the basis of,

- Recorded pulse rate and blood pressure.

- Subjective statement by the patient.

- Visual Analogue Scale (VAS) score.

\section{RESULTS}

A total of 50 patients who underwent open cholecystectomy were included in this study. Both groups were comparable in age, sex, socioeconomic status, duration of symptoms and operative findings. Maximum numbers of patients were in 3160 years age $(60 \%)$ and $78 \%$ were female. Four patients (16\%) in group II discontinued the given mode of analgesia on the operative day onward and counted as non-responsive and were excluded from the study.

An average number of applications of intramuscular diclofenac sodium were 3 from postoperative period to postoperative day 2 . This number was 2.1 for TENS in group II patients.

In group I average duration of pain relief of an operative day and postoperative day 1 was found to be similar, i.e. $8 \pm 0$ hours and on postoperative day 2 is $8.8 \pm 1.63$ hours, and in group II average duration of pain relief is $5.84 \pm .55$ hours in an operated day and $10.8 \pm 2.03$ hours on postoperative day 1 and $11.20 \pm 1.63$ hours on postoperative day 2 . The mean difference was significant between both the groups $(\mathrm{p}<.001)$.

\begin{tabular}{|c|c|c|c|}
\hline & $\begin{array}{c}\text { Operative } \\
\text { Day }\end{array}$ & $\begin{array}{c}\text { Postoperative } \\
\text { Day 1 }\end{array}$ & $\begin{array}{c}\text { Postoperative } \\
\text { Day 2 }\end{array}$ \\
\hline $\begin{array}{c}\text { Group 1 } \\
\text { (mean } \pm \text { sd) }\end{array}$ & $8 \pm 0$ & $8 \pm 0$ & $8.8 \pm 1.63$ \\
\hline $\begin{array}{c}\text { Group II } \\
\text { (mean } \pm \text { sd) }\end{array}$ & $5.84+.55$ & $10.8+2.03$ & $11.20+1.63$ \\
\hline P value & 0.0 & 0.000006 & 0.000004 \\
\hline \multicolumn{2}{|c|}{ Table 1: Average Duration of Pain Relief } \\
\hline
\end{tabular}

As shown in the table below, a maximum number of patients in both the groups after 6 hours of surgery had VAS= 8. At 12 hours, the maximum number of patients had a VAS score of 6 and 8 in group I and that of 4 to 6 in group II. At 24 hours, a maximum number of patients of group I had VAS 4 to 6 and a maximum number of patients of group II had VAS 2 to 4.

\begin{tabular}{|c|c|c|c|c|c|c|c|c|}
\hline \multirow[t]{2}{*}{ Postop } & \multirow[t]{2}{*}{ Groups } & \multicolumn{6}{|c|}{ Visual Analogue Scale Score } & \multirow{2}{*}{ Statistical Significance } \\
\hline & & 0 & 2 & 4 & 6 & 8 & 10 & \\
\hline At 6 hours & $\begin{array}{c}\text { Groups I } \\
\text { Groups II }\end{array}$ & $\begin{array}{l}0 \\
0\end{array}$ & $\begin{array}{l}0 \\
0\end{array}$ & $\begin{array}{l}0 \\
0\end{array}$ & $\begin{array}{l}5 \\
8\end{array}$ & $\begin{array}{l}18 \\
14\end{array}$ & $\begin{array}{l}2 \\
3\end{array}$ & $\mathrm{P}=.498$ \\
\hline At 12 hours & $\begin{array}{l}\text { Groups I } \\
\text { Groups II }\end{array}$ & $\begin{array}{l}0 \\
0 \\
\end{array}$ & $\begin{array}{l}0 \\
0 \\
\end{array}$ & $\begin{array}{c}5 \\
11 \\
\end{array}$ & $\begin{array}{c}10 \\
8 \\
\end{array}$ & $\begin{array}{c}10 \\
6 \\
\end{array}$ & $\begin{array}{l}0 \\
0\end{array}$ & $\mathrm{P}=.176$ \\
\hline At 24 hours & $\begin{array}{l}\text { Groups I } \\
\text { Groups II }\end{array}$ & $\begin{array}{l}0 \\
0\end{array}$ & $\begin{array}{c}6 \\
11\end{array}$ & $\begin{array}{c}7 \\
10 \\
\end{array}$ & $\begin{array}{l}8 \\
4 \\
\end{array}$ & $\begin{array}{l}4 \\
0\end{array}$ & $\begin{array}{l}0 \\
0\end{array}$ & $\mathrm{P}=0.06$ \\
\hline At 48 hours & $\begin{array}{l}\text { Groups I } \\
\text { Groups II }\end{array}$ & $\begin{array}{l}0 \\
0\end{array}$ & $\begin{array}{c}9 \\
23\end{array}$ & $\begin{array}{c}15 \\
2\end{array}$ & $\begin{array}{l}1 \\
0\end{array}$ & $\begin{array}{l}0 \\
0\end{array}$ & $\begin{array}{l}0 \\
0\end{array}$ & $P=0.0$ \\
\hline
\end{tabular}


At 48 hours, a maximum number of patients of group I have VAS 4 and in group II patients had VAS 2 . At 48 hours, the significant association was seen.

\begin{tabular}{|c|c|c|c|c|c|c|c|c|}
\hline & \multicolumn{2}{|c|}{ At 6 Hours } & \multicolumn{2}{c|}{ At 12 Hours } & \multicolumn{2}{c|}{ At 24 Hours } & \multicolumn{2}{c|}{ At 48 Hours } \\
\hline & Group I & Group II & Group I & Group II & Group I & Group II & Group I & Group II \\
\hline Total & 25 & 25 & 25 & 25 & 25 & 25 & 25 & 25 \\
\hline Mean & 7.76 & 7.60 & 6.40 & 5.60 & 4.80 & 3.44 & 3.36 & 2.16 \\
\hline Std. Dev. & 1.05 & 1.29 & 1.52 & 1.63 & 2.08 & 1.47 & 1.11 & .553 \\
\hline P value & \multicolumn{7}{|c|}{.079} & \multicolumn{2}{c|}{.01} & .000 \\
\hline \multicolumn{7}{|c|}{ Table 3: Average VAS Score on Respective Days } \\
\hline
\end{tabular}

The above table shows the average VAS score on the respective days. The mean VAS score difference at 6 and 12 hours were comparable, but at 24 and 48 hours the difference between the two groups found to be statistically significant $(\mathrm{p}<.01$ and $\mathrm{p}<.001)$.

In both groups, there was a significant increase in pulse rate when preoperative values were compared, but the increase gradually plateaued and signifying effectiveness of analgesic effect in both the groups. There was no significant change noticed in systolic and diastolic blood pressure in both groups compared to preoperative status.

\section{DISCUSSION}

Transcutaneous Electrical Nerve Stimulation (TENS) is a commonly used non-pharmacologic and non-invasive treatment for pain. Although, a number of clinical studies show the effectiveness of TENS for pain, there is still much controversy over which conditions to treat with TENS and the adequate parameters to use. TENS therapy can be an alternative pain control method with high effectiveness and fewer complications compared to other techniques. TENS therapy is a practical and beneficial procedure without complications. Patients can easily learn how to apply the electrodes and perform the treatment by themselves. Although, some infrequent complications such as skin hypersensitivity have been published in the literature, no complications due to TENS therapy were seen in our study.[10,11]

VAS scores of groups II were less than the groups I patients. The mean VAS score difference at 6 and 12 hours was found to be comparable and statistically non-significant, but at 24 and 48 hours the difference between two groups was found to be statistically significant. In group I $15(60 \%)$ having VAS 4 and group II 23 (92\%) patients having VAS score 2 at 48 hours postoperatively. The difference between two groups was found to be statistically significant. Thus, it appears that the TENS therapy is effective in controlling the pain cycles and intensity of pain as shown by various studies in the literature.[12,13,14,15,16] Systematic reviews by Walsh et al on TENS for specific types of acute pain have reported that TENS was no better than controls for postoperative pain and labour pain. However, the findings of reviews of TENS for postoperative pain have been challenged because pain measures were taken when patients were allowed free access to analgesic medication. This compromises pain scores because patients in placebo control and TENS groups titrate analgesic medication to achieve effective pain relief, and therefore exhibit similar pain scores. Review authors also included studies that under-dosed TENS or used an inappropriate TENS technique or both. A meta-analysis with subgroup analysis demonstrated a significantly better outcome for TENS when applied using adequate (Optimal) stimulation techniques when compared to non-adequate stimulation techniques.[17]

A number of applications required for TENS were lesser (2.1) than the diclofenac injections (3). This shows that the effectiveness of the TENS therapy, therefore, less no. of visits for the patients to attain satisfactory pain relief which may lead to a better psychological effect on the patient. In our study, $84 \%$ of patients placed on TENS did not require any analgesics in the postoperative period. Therefore, the postoperative pain after cholecystectomy can be controlled effectively by TENS with better patient satisfaction.

When comparing complications due to pain like atelectasis, alveolar collapse, supervening infection, no such complications occurred in the patients of either group in the present study. This may be due to adequate pain relief in both groups.

\section{CONCLUSION}

TENS-induced analgesia had good patient acceptance and is cost effective and TENS can be used as a sole modality to control pain in the outpatients procedure like cholecystectomy with equal efficacy and without any side effects.

\section{REFERENCES}

1. Jensen JE, Conn RR, Hazelrigg G, et al. The use of transcutaneous neural stimulation and isokinetic testing in arthroscopic knee surgery. Am J Sports Med 1985;13(1):27-33.

2. Wang SM, Kain ZN, White P. Acupuncture analgesia I: scientific basis. Anaesth Analg 2008;106(2):602-10.

3. Wang SM, Kain ZN, White PF. Acupuncture analgesia: II clinical considerations. Anaesth Analg 2008;106(2):61121.

4. Reeve J, Menon D, Corabian P. Transcutaneous electrical nerve stimulation: a technology assessment. Int J Technol Assess Health Care 1996;12(2):299-324.

5. Bjordala JM, Johnson MI, Ljunggreena AE. Transcutaneous electrical nerve stimulation can reduce postoperative analgesic consumption a meta-analysis with an assessment of optimal treatment parameters for postoperative pain. Eur J Pain 2003;7(2):181-8.

6. Sluka KA. The neurobiology of pain and foundations for electrical stimulation. In: Robinson AJ, Snyder-Mackler L, editors. Clinical electrophysiology. Lippincott Williams \& Wilkins, Philadelphia 2008;p 107-49.

7. Kat MT, Kogawa EM, Santos CN, et al. TENS and low-level laser therapy in the management of temporomandibular disorders. J Appl Oral Sci 2006;14(2):130-5. 
8. Robinson AJ, Macler LS. Clinical electrophysiology: electrotherapy and electrophysiologic testing. Lippincott Williams \& Wilkins, 2007; $3^{\text {rd }}$ ed:132-3.

9. Forster EL, Kramer JF, Lucy SD, et al. Effect of TENS on pain, medications, and pulmonary function following coronary artery bypass graft surgery. Chest 1994;106(5):1343-8.

10. DeSantana JM, Walsh DM, Vance C, et al. Effectiveness of transcutaneous electrical nerve stimulation for treatment of hyperalgesia and pain. Curr Rheumatol Rep 2008;10(6):492-9.

11. Kaye V. Transcutaneous electrical nerve stimulation emedicine. medscape.com/article/325107.

12. Rosenberg M, Curtis L, Bourke DL. Transcutaneous electrical nerve stimulation for the relief of postoperative pain. Pain 1978;5(2):129-33.
13. Hershman MJ, Cheadle WG, Swift RI, et al. TENS as adjunctive analgesia in patients undergoing elective abdominal procedures. Surg Res Commun 1989;7:65-9.

14. Roche PA, Wright A. An investigation into the value of TENS for arthritic pain. Physiother Theory Practical 1990;6(1):25-33.

15. Sim DT. The effectiveness of transcutaneous electrical nerve stimulation following cholecystectomy. Physiotherapy 1991;77(10):715-22.

16. Akyuz G, Kayhan O, Babacan A, et al. Transcutaneous electrical nerve stimulation in the treatment of postoperative pain and prevention of paralytic ileus. Clinic Rehabil 1993;7(3):218-21.

17. Walsh DM, Howe TE, Johnson MI, et al. Transcutaneous electrical nerve stimulation for acute pain. (Review) The Cochrane Collaboration and published in The Cochrane Library 2011;8:1-70. 